\title{
INDICADORES SOCIAIS por que construir novos indicadores como o IPRS
}

\author{
Haroldo da Gama Torres \\ Maria Paula Ferreira \\ Nádia Pinheiro Dini
}

\begin{abstract}
Resumo: O presente artigo apresenta uma reflexão sobre a experiência da Fundação Seade na construção de indicadores sociais, particularmente o Índice Paulista de Responsabilidade Social - IPRS e seu sistema de indicadores. Também são apresentados os resultados do IPRS 2000.

Palavras-chave: indicadores sociais; dados estatísticos; desenvolvimento humano.
\end{abstract}

Abstract: This article describes the experience of Fundação Seade in creating social indicators, particularly the São Paulo Index of Social Responsibility - IPRS and its system of indicators. It includes a presentation of the results of IPRS 2000.

Key words: social indicators; statistical data; human development.

$\mathrm{E}$ ntre as aspirações das agências produtoras de dados e informações estatísticas - como o Seade uma das mais importantes talvez seja a de que os formuladores de políticas públicas utilizem efetivamente a sua produção para o planejamento e a avaliação de políticas. Em tese, a utilização de informações e resultados estatísticos, tanto na definição de metas como na priorização e direcionamento das intervenções, possibilitariam mais rapidez e eficiência ao gestor público para atingir seus diferentes objetivos. Entre outras coisas, as estatísticas constituem instrumento importante para: desenvolver melhor as políticas sociais, permitindo o acompanhamento e a evolução dos processos; aumentar o consenso social sobre as difíceis escolhas diante do sempre presente constrangimento dos recursos; revelar e criar responsabilidades dos diferentes atores envolvidos nesses processos; e incluir na agenda de políticas sociais temas muitas vezes negligenciados no campo de ação de determinada política setorial (como a questão racial, por exemplo).

Atualmente, é crescente a demanda que a Fundação Seade recebe tanto de órgãos públicos como da mídia para fornecer e organizar estatísticas. Portanto, essa procura é um indício de que essa aspiração e esse desafio vêm-se concretizando. Responder a esse desafio não é trivial. Envolve não apenas a organização de bancos de dados e seu tratamento, mas a compreensão de como a informação é apreendida e utilizada pelos usuários. Existe relativo consenso de que a melhor (e mais arriscada) forma de "comunicar" complexos fenômenos sociais de modo mais simples tem sido pela utilização de indicadores, no que pese as dificuldades e os problemas metodológicos envolvidos na elaboração desses instrumentos.

Nesse sentido, a proposta deste artigo é produzir uma reflexão a respeito da produção de indicadores, seus riscos e suas possibilidades. Em particular, descrevemos aqui a experiência da instituição no processo de construção de indicadores sintéticos de desenvolvimento em nível municipal, especificamente os que compõem o sistema de indicadores do Índice Paulista de Responsabilidade Social - IPRS. Esses indicadores foram criados no Fórum São Paulo - Século XXI, por solicitação de seus componentes, que requereram a construção de indicadores sintéticos que permitissem captar, de forma contínua, a progressão do desenvolvimento dos municípios paulistas em direção à sociedade desejada e discutida amplamente nesse Fórum. 


\section{ÍNDICE DE DESENVOLVIMENTO HUMANO}

Um dos principais responsáveis por esse renovado interesse por estatísticas para políticas sociais é o Índice de Desenvolvimento Humano - IDH, lançado no início dos anos 90 e que, rapidamente, tornou-se a mais conhecida das medidas de desenvolvimento. Valendo-se do impressionante sucesso do IDH, as Nações Unidas tornaram-se capazes de sinalizar aos governantes dos diversos países e regiões em desenvolvimento, a proposição de que buscar crescimento não é sinônimo exclusivo de fazer aumentar a produção. No bojo desta questão, tem sido possível constituir um considerável debate internacional a respeito de que, pelo menos, a melhoria das condições de saúde e educação da população deve também ser considerada como parte fundamental do processo de desenvolvimento.

A construção desse novo indicador de desenvolvimento reflete a estreita relação com os debates em torno da mensuração da qualidade de vida. A rigor, um indicador sobre esse tema se baseia na admissão de que a qualidade de vida não se resume à esfera econômica da experiência humana. A grande questão que se coloca quando se pretende avaliar o nível de prosperidade ou qualidade de vida de um país, região ou município é como fazê-lo. Quais as informações necessárias? E talvez o mais importante, quais os critérios verdadeiramente significativos para o desenvolvimento humano.

É possível que a medida de qualidade de vida mais difundida, até o surgimento do IDH, tenha sido o PIB per capita. No entanto, conhecer o PIB per capita de um país ou região não é suficiente para avaliar as condições de vida de sua população, uma vez que, também, é necessário conhecer a distribuição desses recursos e como se dá $o$ acesso a eles.

Esse entendimento, de que o PIB per capita é uma medida insuficiente para avaliar a qualidade de vida das pessoas, já estava evidente na década de 50 , quando em 1954 um grupo de especialistas das Nações Unidas propôs que, além da dimensão monetária, outras dimensões deveriam ser consideradas na avaliação da qualidade de vida das pessoas.

Essa idéia se baseia no pressuposto de que o progresso de um país ou localidade não pode ser mensurado apenas pelo dinheiro que possuem (ou carecem) seus cidadãos, mas também em sua saúde, na qualidade dos serviços médicos e em sua educação. Essas medidas deverão ser consideradas não só pela disponibilidade mas também pela qualidade. Da mesma forma, é necessário conhecer as condições de trabalho, quais direitos legais e políticos usufruem seus cidadãos, que liberdades possuem para conduzir suas relações sociais e pessoais, como se estruturam as relações familiares e entre os gêneros e como estas estruturas promovem ou dificultam outros aspectos da atividade humana. E, sobretudo, saber de que forma a sociedade em questão permite às pessoas imaginar, maravilhar-se e sentir emoções, o que efetivamente faz com que a vida seja mais do que um conjunto de relações comerciais (Nussbaum e Sen, 1998).

A ênfase em diferentes componentes para a mensuração da qualidade de vida implica considerar vários aspectos, que não são transferíveis entre si. Não é suficiente conhecer somente as condições econômicas, também deve-se ter informações sobre a saúde, conhecimento e habilidades, relações sociais, condições de trabalho, etc., para medir o nível de vida. O IDH propôs-se a enfrentar este desafio, sintetizando em um único indicador dimensões de renda, longevidade e escolaridade.

Apesar de o sucesso alcançado pelo IDH, a escolha das dimensões cobertas pelo índice bem como as estratégias de ponderação e de operacionalização das diferentes dimensões têm provocado bastante desconforto na comunidade produtora de dados. Não poderia ser diferente, pois quem lida com estatísticas sociais sabe que ao reduzir em um único número a complexa evolução e dinâmica do desenvolvimento social e econômico, faz-se uma série de reduções e simplificações, muitas vezes difíceis de serem captadas por não-especialistas ou mesmo aplicadas no âmbito do senso comum.

Apesar dessas objeções, é inegável a importância do IDH como medida catalisadora, que introduz na agenda temas em que as Nações Unidas gostariam de ver ventiladas. Nas palavras de Sen “... o índice imperfeito falou alto e claro e recebeu uma atenção inteligente e, através desse veículo, a realidade complexa contida no Relatório ${ }^{1}$ encontrou também uma audiência interessada" (PNUD, 1998).

Simultaneamente ao processo de difusão do IDH nos anos 90, há uma nova ênfase em políticas sociais descentralizadas, focalizadas e que envolvem a participação de atores não governamentais. Isso reforça a demanda por diferentes tipos de indicadores ao nível nacional e local. Com o advento do IDH, há um verdadeiro boom na produção de indicadores sintéticos para países, Estados, municípios e até distritos ou bairros em diferentes países em desenvolvimento, como Índia, Honduras, Guatemala, Costa Rica e Brasil (PNUD, 1999; PNUD, 2000). ${ }^{2}$ 
Uma vez que, com o avanço da descentralização, a mensuração do desenvolvimento tornou-se mais central para os governos locais e nacionais que pretendem introduzir políticas de desenvolvimento social e econômico no local. O principal motivo desse comportamento parece ser o fato de que os indicadores são vistos como poderosas ferramentas, não somente para o planejamento, mas também como formas dos governos democráticos se relacionarem com a opinião pública e a mídia e com as pressões vindas dos políticos tradicionais e demais forças locais (PNUD, 2000).

Existe pouca certeza a respeito de que indicador ou indicadores seriam adequados ou suficientes, especialmente se o pesquisador considera a questão do ponto de vista de uma política pública específica quanto ao local (Inforegio, 2000). Assim, quando um gestor de políticas públicas pretende utilizar um indicador como ferramenta de avaliação e acompanhamento da política social, algumas questões importantes precisam ser analisadas: Como produzir um indicador para pequenas áreas? Este indicador será sensível a variações de curto prazo? Ou seja, é condizente com o tempo de execução da política social? Estas são apenas algumas das várias questões que surgem quando os gestores públicos e a sociedade tornam-se demandantes de indicadores que serão utilizados para tomadas de decisões e avaliações.

Em geral, deve-se considerar que:

- a percepção de que algumas regiões são desenvolvidas e outras não está no centro dos principais dilemas das políticas nacionais e internacionais do último século, particularmente desde o processo de descolonização. No entanto, a construção de medidas de desenvolvimento não é simples. Ela implica identificar, medir e comparar as dimensões que caracterizam esse fenômeno, bem como suas transformações ao longo do tempo;

- apesar de serem na teoria ferramentas ideais para políticas públicas, os indicadores criados dificilmente possuem, ao mesmo tempo, os atributos classicamente tidos como indispensáveis a um bom indicador, como: credibilidade, simplicidade, desagregação espacial, reprodutibilidade, comparabilidade, periodicidade, acurácia, baixo custo e sensibilidade;

- muitas políticas sociais são planejadas e aplicados para um período relativamente pequeno, em geral um mandato governamental. Assim, os indicadores deveriam poder expressar as variações ocorridas nesse intervalo de tempo, o que não é fácil, diante da lógica do processo de coleta e produção de dados;
- a maioria dos indicadores construídos refere-se a valores agregados para áreas específicas, tais como médias de renda ou de anos de estudo. Isso pode encobrir importantes desigualdades existentes dentro das áreas, ou mesmo situações de segregação. Nesse caso, a unidade geográfica é muito importante, uma vez que, quanto menor o tamanho da área maior a possibilidade de identificar situações de desigualdades e/ou segregação. Esse fato é particularmente importante quando se constrói índices para municípios de diferentes portes populacionais com a pretensão de compará-los;

- em regimes democráticos, o processo de formulação de políticas envolve convencimento e geração de consensos. Assim, as variáveis utilizadas para orientar as estratégias de uma particular política social devem ser simples e desfrutar de muita credibilidade no governo, tanto interna como externamente.

Em síntese, a demanda por novos índices parece ser parte de uma tendência dos governantes de tornar cada vez mais racionais os processos de tomadas de decisão. Soma-se a isso a maior utilização dos indicadores pela sociedade civil e pela mídia, que os utilizam para traçar um panorama da questão social nacional ou local.

Assim, ao passarem também a produzir indicadores, em especial os sintéticos, várias organizações produtoras de dados entenderam que, apesar de suas limitações, eles podem transformar-se em mensagens fortes e, nesta condição, tornarem-se aliadas na criação de uma cultura de responsabilidade e na realização efetiva dos direitos humanos, ambos comportamentos indispensáveis para a construção de sociedades que anseiam por um desenvolvimento sustentável e com a democratização da sociedade do conhecimento. No entanto, estamos bem longe de produzir indicadores que respondam efetivamente a todos os requisitos desejáveis do ponto de vista de sua perfeita utilização por parte dos gestores públicos. A seguir, alguns esforços realizados pelo Seade nesse campo.

\section{POR QUE CONSTRUIR O IPRS}

O Índice Paulista de Responsabilidade Social - IPRS passou a ser desenvolvido pela Fundação Seade em 2000, após uma encomenda de um índice que refletisse o desenvolvimento e a qualidade de vida dos municípios paulistas. A construção desse indicador partiu, a princípio, de uma avaliação das experiências com outros indicadores municipais, particularmente o IDH-M (o IDH desenvolvido para municípios do Brasil). Avaliou-se que este indicador, no 
caso de São Paulo, apresentava pouca diferenciação entre as diversas situações socioeconômicas observadas nos municípios paulistas, e não era adequado aos objetivos da Assembléia Legislativa.

Uma das primeiras tarefas na construção do IPRS referia-se ao problema de como combinar as diferentes dimensões (renda, escolaridade, etc.) que se deseja representar no índice. O IDH tinha optado pela média aritmética, opção simples mas arbitrária. Contudo, dentro do paradigma adotado para a construção do IPRS, no qual a mensuração da qualidade de vida pressupõe considerar vários aspectos não transferíveis entre si, nenhuma das dimensões poderia ser utilizada para substituir a outra, nem hierarquizável. Dessa forma, não existe forma objetiva ou imparcial pela qual seria possível decidir qual de duas pessoas está melhor, se uma delas possui, por exemplo, uma saúde deficiente, porém melhores condições socioeconômicas que a outra.

A rigor, ao se considerar a qualidade de vida como multidimensional, duas questões surgem. A primeira é o fato de que não existe nenhuma teoria universal que aponte quais componentes são essenciais para a mensuração da qualidade de vida. É desejável que esses componentes reflitam os problemas que afetam todas as condições de vida e sejam de tal importância que em todas as sociedades se façam esforços organizados e coletivos para combatê-los. Erikson (1998), discutindo a experiência sueca, alerta para o fato de que esses componentes dependem da situação e cultura do lugar. Destaca também o caráter político das escolhas, selecionando-se somente os componentes passíveis de sofrerem intervenção pelas políticas públicas.

A segunda questão é o fato de que a multidimensionalidade implica tornar impossível a elaboração de um único indicador ordenável de condições de vida. Assim, uma das formas de contornar esse "problema" seria a descrição das condições de vida feita com base em um conjunto de indicadores que expressariam a situação da população estudada para cada uma das dimensões consideradas na mensuração da qualidade de vida. A desvantagem desse tipo de abordagem é o grande número de indicadores necessários e a dificuldade na visualização de uma imagem geral das condições de vida.

Uma alternativa a esse enfoque é a criação de uma tipologia que permita distinguir as diferentes situações que configuram as condições de vida de uma população. Observe-se, entretanto, que esse procedimento de classificação, mesmo incapaz de ordenar essas situações, permite distingui-las claramente, o que, com certeza, é o que im- porta quando se pensa no desenho de políticas públicas específicas para cada grupo de municípios. ${ }^{3}$

O sistema de indicadores IPRS, cujo objetivo é permitir a caracterização e o acompanhamento da evolução dos municípios paulistas, foi organizado valendo-se da idéia de que a tipologia de municípios é um modo mais transparente de hierarquizar as diferentes situações sociais observadas do que por qualquer estratégia arbitrária de ponderação. Ele é originalmente composto por um conjunto de indicadores sintéticos que mais à frente derivam diferentes tipos de municípios. Pelo IPRS, é possível o agrupamento de municípios de acordo com as características relevantes para a definição de prioridades de ação e, no interior de cada grupo, a construção de rankings de municípios, segundo os indicadores específicos. Outra característica do sistema IPRS é permitir a identificação dos problemas que colocam os municípios em situação de vantagem ou desvantagem em relação aos demais municípios do Estado de São Paulo. ${ }^{4}$

\section{Índice Paulista de Responsabilidade Social}

Tomando-se por base esses desafios, considerou-se que o indicador a ser construído deveria conter certas especificidades. A primeira seria preservar as três dimensões que compõem o IDH - renda, longevidade e escolaridade -, tendo em vista o interesse em se manter consistente com o paradigma do desenvolvimento humano proposto pelo PNUD. A segunda, a inclusão de variáveis capazes, na medida do possível, de captar mudanças de curto prazo e os esforços dos municípios em relação às três dimensões consideradas. Em terceiro lugar, basear-se prioritariamente em registros administrativos, por causa da cobertura e periodicidade dessas fontes de dados, o que permitiria a atualização do indicador para os anos entre os censos demográficos e para todos os municípios do Estado de São Paulo. Assim, as variáveis escolhidas para compor são distintas daquelas empregadas no cálculo do IDH, apesar de representarem as mesmas dimensões: renda, longevidade e escolaridade.

Para cada uma das três dimensões consideradas, foram criados, para 1992, 1997 e 2000, indicadores sintéticos que permitem a hierarquização dos municípios paulistas conforme seus níveis de riqueza, longevidade e escolaridade. Esses indicadores estão expressos em uma escala de 0 a 100 e se constituem em uma combinação linear das variáveis selecionadas para compor o indicador sintético. A estrutura de ponderação foi obtida de acordo com um 
QUADRO 1

Síntese das Variáveis Selecionadas e Estrutura de Pesos Adotada, segundo Dimensões do IPRS

\begin{tabular}{|c|c|}
\hline Dimensões & Variáveis \\
\hline \multirow[t]{4}{*}{ Riqueza Municipal } & Consumo de energia elétrica residencial (44\%) \\
\hline & Consumo de energia elétrica na agricultura, no comércio e em serviços ( $23 \%)$ \\
\hline & Rendimento médio dos empregados com carteira assinada e do setor público (19\%) \\
\hline & Valor adicionado per capita (14\%) \\
\hline \multirow[t]{4}{*}{ Longevidade } & Mortalidade infantil (30\%) \\
\hline & Mortalidade de adultos de 60 anos e mais (20\%) \\
\hline & Mortalidade de adultos de 15 a 39 anos (20\%) \\
\hline & Mortalidade perinatal (30\%) \\
\hline \multirow[t]{5}{*}{ Educação } & Porcentagem de jovens de 15 a 19 anos que concluíram o ensino fundamental (26\%) \\
\hline & Porcentagem de jovens de 20 a 24 anos que concluíram o ensino médio (24\%) \\
\hline & Porcentagem de crianças de 10 a 14 anos alfabetizadas (24\%) \\
\hline & Porcentagem de jovens de 15 a 24 anos alfabetizadas (23\%) \\
\hline & Porcentagem de matrículas de ensino fundamental oferecidas pela rede municipal ( $3 \%)$ \\
\hline
\end{tabular}

Fonte: Fundação Seade. IPRS

modelo de análise fatorial, em que se estuda a estrutura de interdependência entre diversas variáveis. O Quadro 1 apresenta as variáveis que compõem os três indicadores sintéticos e a estrutura de ponderação obtida para cada uma das dimensões consideradas.

O indicador riqueza municipal procura captar, ao mesmo tempo, a riqueza do município (por intermédio das variáveis: consumo de energia elétrica na agricultura, no comércio e em serviços e valor adicionado per capita) e a renda familiar (por meio das variáveis: consumo de energia elétrica residencial e rendimento médio dos empregados no setor privado com carteira assinada e setor público). Esse indicador pode ser reproduzido anualmente, uma vez que isso ocorre também nas variáveis que o compõem. As fontes de informação utilizadas foram os registros administrativos fornecidos pelas Secretarias de Estado dos Negócios da Fazenda e da Energia do Estado de São Paulo e do Ministério do Trabalho e Emprego.

$\mathrm{O}$ indicador de longevidade, expresso pela combinação de quatro taxas de mortalidade específicas a determinadas faixas etárias - mortalidade perinatal, infantil, de adultos de 15 a 39 anos e a de pessoas de 60 anos e mais - pretendeu destacar as dimensões da mortalidade consideradas relevantes para o estudo da qualidade de vida no Estado de São Paulo. Assim, devido às especificidades do Estado, com crescente mortalidade de adultos e significativos problemas de óbitos maternos e perinatais, que abrange os natimortos, enfatizouse essas dimensões. As fontes de informação utilizadas fo- ram os dados do registro civil, organizados e disponibilizados pela Fundação Seade.

A opção por um indicador fundamentado em quatro tipos de mortalidade, em detrimento da esperança de vida que, a rigor, permite captar as condições médias da mortalidade de determinada região para todos os diferentes grupos de idade, baseou-se no fato de que a esperança de vida carrega forte componente inercial e, portanto, de pouca sensibilidade a variações conjunturais e incapaz de revelar as particularidades da mortalidade em diferentes regiões.

Na construção do indicador de escolaridade, enfatizouse a situação escolar dos adolescentes e jovens. As razões para isso foram, em primeiro lugar, o fato de que o nível de escolaridade dos jovens e adolescentes reflete, com maior precisão, a situação geral do sistema de ensino nos últimos anos. Em segundo lugar, como os jovens comporão no futuro a força de trabalho. Os locais com menor escolaridade de jovens tendem e tenderão a ter, em geral, mais problemas no que diz respeito à inserção desses indivíduos no mundo do trabalho, uma vez que esse mercado é crescentemente seletivo de acordo com a escolaridade.

Diferentemente dos indicadores de riqueza municipal e longevidade o de escolaridade é embasado em dados primários: censos demográficos e contagem da população. A principal razão para isso foi a ocorrência de mudanças, na década de 90, no questionário do censo escolar - fonte alternativa para a produção desses indicadores - que dificultou a construção de séries históricas. 
QUADRO 2

Síntese dos Critérios Adotados para a Formação dos Grupos de Municípios

\begin{tabular}{ll}
\hline Grupos & Categorias \\
\hline Grupo 1 & Alta riqueza, média longevidade e alta escolaridade \\
& Alta riqueza, média longevidade e média escolaridade \\
& Alta riqueza, baixa longevidade e alta escolaridade \\
& Alta riqueza, alta longevidade e baixa escolaridade \\
& Alta riqueza, alta longevidade e média escolaridade \\
& Alta riqueza, alta longevidade e alta escolaridade
\end{tabular}

Grupo 2 Alta riqueza, baixa longevidade e baixa escolaridade Alta riqueza, média longevidade e baixa escolaridade Alta riqueza, baixa longevidade e média escolaridade

Grupo 3 Baixa riqueza, média longevidade e média escolaridade Baixa riqueza, alta longevidade e média escolaridade Baixa riqueza, média longevidade e alta escolaridade Baixa riqueza, alta longevidade e alta escolaridade

Grupo 4 Baixa riqueza, baixa longevidade e média escolaridade Baixa riqueza, baixa longevidade e alta escolaridade Baixa riqueza, média longevidade e baixa escolaridade Baixa riqueza, alta longevidade e baixa escolaridade

Grupo 5 Baixa riqueza, baixa longevidade e baixa escolaridade Fonte: Fundação Seade. IPRS.

O indicador de escolaridade é bastante assemelhado ao IDH, que combina as taxas de matrícula nos ensinos fundamental, médio e superior com os níveis de analfabetismo adulto. De modo geral, as taxas de conclusão refletem as condições gerais de ensino, enquanto as de analfabetismo, que inclui as pessoas analfabetas e com até 1 ano de estudo, indicam a proporção de indivíduos totalmente excluídos do sistema escolar, apontando para a questão dos níveis de exclusão.

Com a combinação dos três indicadores, foi criada uma tipologia que classifica os 645 municípios do Estado de São Paulo em cinco grupos com características similares de riqueza municipal, longevidade e escolaridade. A tipologia de municípios criada constitui-se em ferramenta analítica que permite identificar a situação de cada um dos municípios paulistas em cada uma das três dimensões da análise. Da mesma forma, nenhuma delas é privilegiada a despeito de outra.

A construção dessa tipologia baseou-se em técnicas estatísticas multivariadas (Seade, 2001) que agrupam municípios de acordo com a similaridade existente entre eles nas três dimensões consideradas. Para fins de simplificação da descrição dos grupos criados e sua posterior reprodução, sintetizou-se os três indicadores sintéticos de riqueza municipal, longevidade e escolaridade em escalas categóricas, que expressam o "padrão geral" dos grupos criados. Para os indicadores de longevidade e escolaridade, foram identificadas três categorias - Baixa, Média e Alta - e para o de riqueza municipal duas categorias Baixa e Alta. O Quadro 2 apresenta a descrição dos cinco grupos de municípios.

\section{Resultados do IPRS 2000}

Os Mapas de 1 a 3 apresentam a distribuição dos municípios conforme os indicadores sintéticos de riqueza, longevidade e escolaridade, principais resultados obtidos por meio da reprodução da tipologia de municípios em 2000.

Por estes mapas, é possível observar em primeiro lugar a concentração dos municípios mais ricos na Região Metropolitana de São Paulo, em parte do litoral e no eixo em torno das rodovias Anhangüera e Presidente Dutra (Mapa 1). Para o indicador de longevidade, Mapa 2, notase uma grande concentração de municípios localizados nas regiões sul e leste, incluindo partes do Vale do Paraíba, com baixos níveis de longevidade. A maior parte dos municípios do Estado apresenta níveis médios e altos de longevidade, com grande concentração no oeste de municípios com altos níveis de longevidade. No indicador de escolaridade, Mapa 3, observa-se um padrão semelhante ao apresentado pelo indicador de longevidade, destacando-se o melhor perfil do Estado em relação a este indicador.

O Mapa 4 apresenta as distintas situações existentes entre os municípios paulistas, e é possível traçar um perfil dos municípios que compõem cada um dos cinco agrupamentos:

- Grupo 1: composto por 81 municípios localizados ao longo das principais rodovias do Estado de São Paulo Presidente Dutra e Anhangüera. É o maior grupo na questão populacional com aproximadamente 23 milhões de habitantes. Fazem parte deste grupo os municípios de São Paulo, Campinas, Ribeirão Preto, São José dos Campos, Sorocaba e Santos entre outros. Os municípios desse grupo se destacam em relação aos demais municípios do Estado por apresentar, ao mesmo tempo, níveis mais elevados de riqueza e nos indicadores sociais.

- Grupo 2: formado por 48 municípios, cerca de $5 \mathrm{mi}-$ lhões de pessoas, localizados sobretudo no entorno das Regiões Metropolitanas de São Paulo, Campinas e Baixada Santista, caracteriza-se por apresentar um perfil de 
MAPA 1

Indicador Sintético de Riqueza Municipal

2000

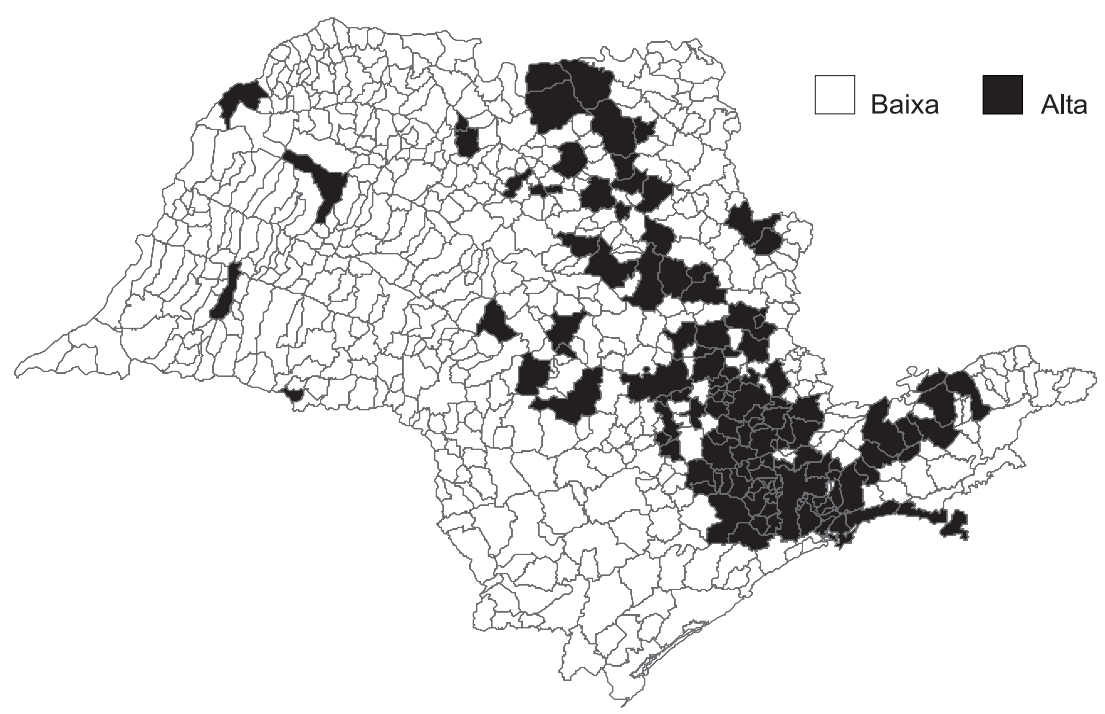

Fonte: Fundação Seade. IPRS.

MAPA 2

Indicador Sintético de Longevidade

2000

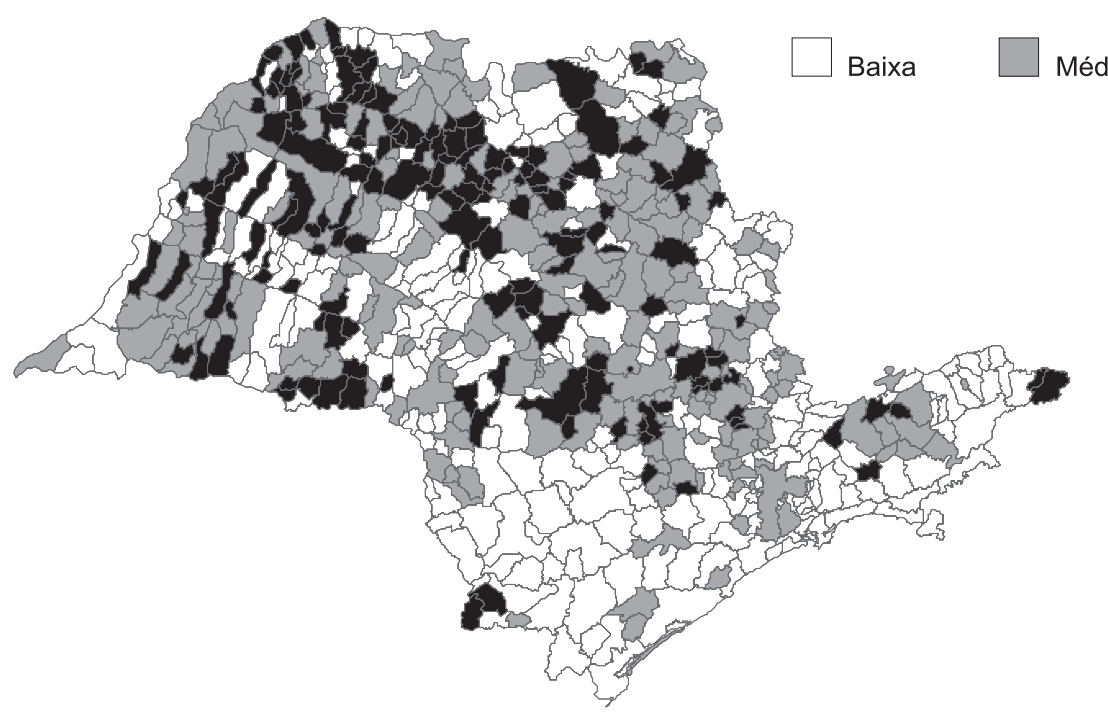

Fonte: Fundação Seade. IPRS 
MAPA 3

Indicador Sintético de Escolaridade

2000

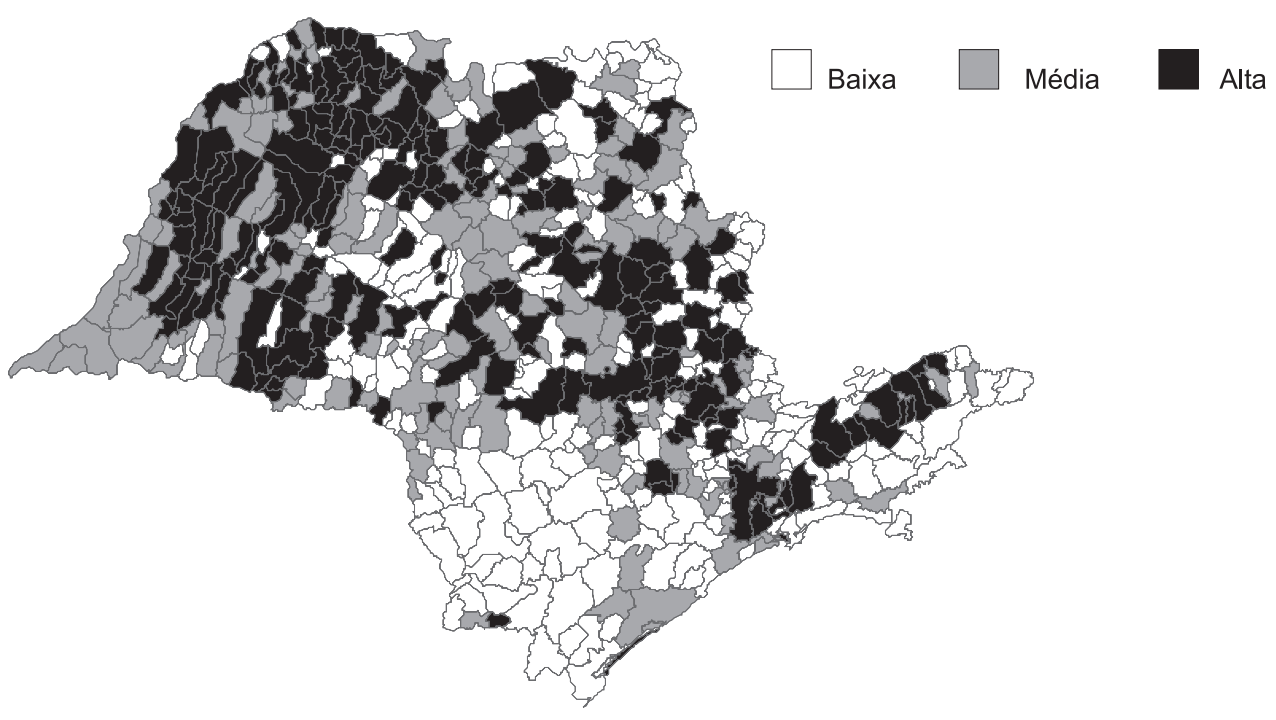

Fonte: Fundação Seade. IPRS.

MAPA 4

Índice Paulista de Responsabilidade Social

2000

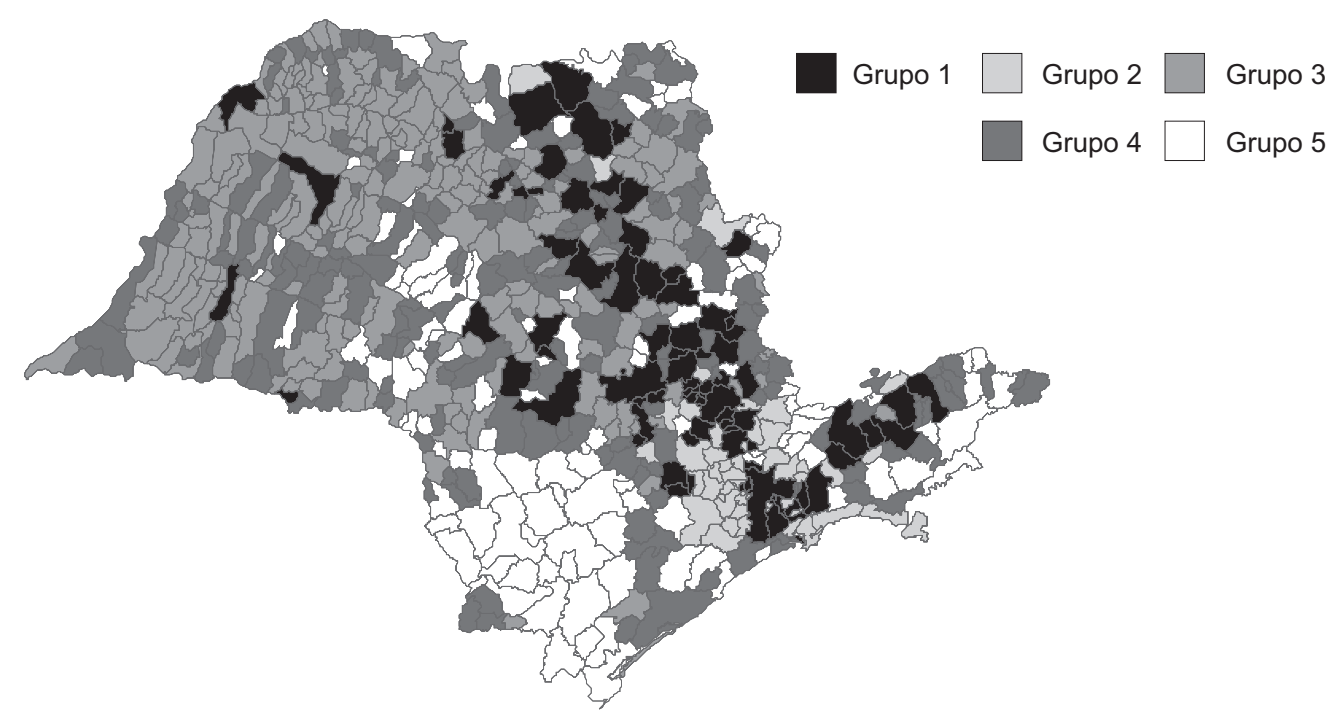

Fonte: Fundação Seade. IPRS 
relativa riqueza municipal e situação social inadequada com precárias condições de longevidade e escolaridade. Identificam-se, neste conjunto de municípios, três importantes segmentos: 1) municípios industriais, como Mauá, Cubatão, Diadema e Guarulhos, localizados nos entornos das regiões metropolitanas, cuja riqueza municipal pode ser considerada elevada devido, sobretudo, à presença de indústrias de grande porte; 2) municípios que abrigam condomínios de alto padrão, como Barueri, Cotia e Itapecerica da Serra; 3 ) municípios turísticos, tais como Guarujá, Campos do Jordão, Ilhabela, Ibiúna e Atibaia.

- Grupo 3: engloba 211 municípios; em geral, são de pequeno porte, baixo nível de riqueza municipal e elevadas condições de escolaridade e de longevidade, quando comparados ao restante do Estado de São Paulo. Localizam-se nas regiões norte e oeste do Estado, com uma população de 3,5 milhões de habitantes, ou uma média de 16,7 mil habitantes. Quanto ao porte populacional, as exceções são Franca e Santa Bárbara d'Oeste, ambos com mais de 100 mil habitantes. Entre as possíveis explicações para a emergência destas localidades está seu pequeno tamanho populacional, que, em tese, é um elemento que poderia tornar mais transparentes e eficazes os instrumentos de política de descentralização em saúde e educação. Além disso, os dados demográficos disponíveis apontam para a continuidade do padrão histórico de emigração nestas áreas. Em princípio, esse elemento torna menos premente a necessidade de investimentos em infra-estrutura viária para a urbanização de novas áreas.

- Grupo 4: agrega 191 municípios, com 3,5 milhões de habitantes, que, de modo geral, apresentam baixo nível de riqueza municipal e níveis intermediários de escolaridade e/ou longevidade. Esses municípios estão localizados em quase todas as regiões do Estado, com destaque para áreas tradicionalmente consideradas problemáticas.

- Grupo 5: formado por localidades tradicionalmente pobres, caracterizadas por baixos níveis de riqueza municipal, longevidade e escolaridade. Este grupo concentra os piores municípios do Estado, tanto em riqueza como nos indicadores sociais. Seus 114 municípios localizamse em áreas bem específicas do Estado, como o Vale da Ribeira e as Serras do Mar e da Mantiqueira. Sua população total é de apenas 2 milhões de habitantes.

Entre os resultados apresentados, é possível identificar os perfis específicos de cada um dos cinco agrupamentos e também perceber padrões espaciais que demonstram que os indicadores gerados caracterizam, de forma efetiva, a heterogeneidade regional do Estado de São Paulo. Segundo essa classificação, os municípios pertencentes ao Grupo 1 localizam-se principalmente ao longo do eixo das Rodovias Dutra e Anhangüera, e têm o Município de São Paulo como vértice; os municípios do Grupo 2 concentram-se nos entornos metropolitanos de São Paulo, Campinas e Baixada Santista; já os municípios do Grupo 3 encontram-se, principalmente, no oeste do Estado; enquanto os municípios dos Grupos 4 e 5 tendem, por sua vez, a ficar mais concentrados nos bolsões de pobreza do Vale do Ribeira e das Serras do Mar e da Mantiqueira.

Quando se comparam esses resultados com os obtidos em 1997, observa-se a permanência do padrão já identificado naquele ano. Apesar de não ser objeto deste artigo a comparação da evolução dos indicadores setoriais entre esses dois períodos, é interessante salientar os expressivos progressos nas dimensões de longevidade e, principalmente, escolaridade. Quanto aos níveis de riqueza municipal, praticamente, não houve alteração entre os anos 1997 e $2000 .^{5}$

\section{CONSIDERAÇÕES FINAIS}

O IPRS compartilha com o IDH a perspectiva de que o desenvolvimento é um processo que, além dos aspectos econômicos, necessita incorporar dimensões da vida social e da qualidade de vida dos indivíduos.

O IPRS, idealizado como um diálogo com o IDH e com o paradigma do desenvolvimento humano, incorpora certas especificidades decorrentes das condições particulares do Estado de São Paulo:

- priorização de indicadores que produzem variações num período de quatro ou cinco anos, que corresponde ao tempo de uma gestão governamental, constituindo-se assim em uma importante ferramenta para o monitoramento de políticas públicas;

- criação, não de um único índice, mas de uma tipologia de municípios que agregam características comuns, possibilitando a identificação dos principais problemas econômicos ou sociais de um município;

- indicadores do IPRS são fundamentados em critérios relativos, definidos com base na situação apresentada pelo próprio Estado. Este fato permite a construção de um quadro muito mais heterogêneo da diversidade paulista do que o proporcionado pelo IDH, que utiliza escalas ajustadas à heterogeneidade observada na comparação entre os diversos países. 
Assim, esse conjunto de indicadores fornece mais subsídios para se refletir a respeito dos elementos que induzem diferentes performances econômicas e sociais dos municípios paulistas. No entanto, a continuidade dessa proposta apresenta novos e importantes desafios, e um dos mais importantes é a compreensão sobre a heterogeneidade existente no interior do município. Pois, apesar de o IPRS revelar a heterogeneidade existente entre os municípios, há também uma heterogeneidade no interior de cada município, implicando desafios às políticas públicas estaduais e municipais, em especial no campo do combate à pobreza. Uma vez que, mesmo os municípios mais ricos do Estado, como São Paulo e Campinas, apresentam em seu interior significativos bolsões de pobreza, que constituem recorrente dificuldade para uma satisfatória resolução de seus problemas sociais.

Nesse sentido, vêm sendo desenvolvidos, em uma segunda etapa do IPRS, estudos que objetivam captar a heterogeneidade intra-urbana, utilizando-se dos Setores Censitários, como unidade geográfica e dos dados dos Censos Demográficos. Da mesma forma, está se buscando a criação de indicadores que permitam captar os esforços municipais para melhorar a situação de seus habitantes nos campos da saúde e educação. ${ }^{6}$

\section{NOTAS}

1. Trata-se do Relatório de Desenvolvimento Humano publicado anualmente pelo Programa da Nações Unidas para o Desenvolvimento (PNUD).

2. No Brasil, existem mais de 10 diferentes índices produzidos para municípios (PNUD et al., 1998; Seade, 2001) e intramunicipais para grandes cidades como São Paulo, Curitiba, Porto Alegre, Santo André, Belo Horizonte, Rio de Janeiro, Recife, Campinas e Brasília. Parte dessa produção pode ser encontrada na Internet em: <www.pbh.gov.br>; $<$ www.ipea.gov.br $>$ e $<$ www.undp.org.br $>$.

3. Ressalte-se, porém, que a opção pela criação de um único indicador, no caso do IDH, mostrou-se bastante adequada a seu objetivo de ordenar de forma simples e inteligível unidades geográficas, segundo o grau de desenvolvimento humano.

4. A Fundação Seade já possuía experiência na criação de tipologias, como os grupos socioeconômicos da Pesquisa de Condições de Vida na Região Metropolitana de São Paulo, realizada em 1990.

5. Uma análise detalhada da evolução dos indicadores IPRS está apresentada no relatório do IPRS (Fundação Seade, 2003a).

6. Para maiores detalhes ver relatório do IPRS (Fundação Seade, 2003b; c).

\section{REFERÊNCIAS BIBLIOGRÁFICAS}

DEBRAJ, R. Development economics. New Jersey: Princeton University Press, 1998.
ERIKSON, R. Descripciones de la desigualdad: el enfoque sueco de la investigación sobre el bienestar. In: NUSSBAUN, M.; SEN, A. (Comp.). La calidad de vida. México: Fondo de Cultura Económica; The United Nations University, 1998.

FUNDAÇÃO SEADE. Índice paulista de responsabilidade social. Atualização. São Paulo: Assembléia Legislativa de São Paulo, $2003 a$.

Índice paulista de responsabilidade social. Cluster de pobreza região administrativa de Campinas. São Paulo: Assembléia Legislativa de São Paulo, 2003 b.

. Índice paulista de responsabilidade social. Geração do indicador de esforços em saúde. São Paulo: Assembléia Legislativa de São Paulo, 2003c.

Índice paulista de responsabilidade social. São Paulo: Assembléia Legislativa de São Paulo, 2001.

Cadernos do fórum: São Paulo, século XXI. São Paulo: Assembléia Legislativa de São Paulo, 2000.

Prestação de serviços para a elaboração do projeto priorizando o saneamento no Estado de São Paulo. São Paulo, 1998a. Mimeografado.

Prestação de serviços especializados de consultoria para a realização de estudos, pesquisas, análises, sistematização, georreferenciamento e disseminação de indicadores socioeducacionais para o Estado de São Paulo. São Paulo: 1998b. Mimeografado. $1-6$.

São Paulo no limiar do século XXI. São Paulo, 1993, v. Pesquisa de condições de vida na região metropolitana de São Paulo: uma abordagem multissetorial. São Paulo, 1992.

GOUVÊA, G. Uma salto para o presente: a educação básica no Brasil. São Paulo em Perspectiva, São Paulo, Fundação Seade, v.14, n.1, 2000.

HADDAD, S.; PIERRO, M. Satisfação das necessidades básicas de aprendizagem de jovens e adultos no Brasil: uma avaliação da década da educação para todos. São Paulo em Perspectiva, São Paulo, Fundação Seade, v.14, n.1, 2000.

IBASE. Observatório da Cidadania, n. 3. Rio de Janeiro, 1999a. Cadernos do Observatório, n. 0. Rio de Janeiro, 1999b. Observatório da Cidadania, n.2. Rio de Janeiro, 1998.

INFOREGIO. The urban audit: toward a benchmark of quality of life in 58 European Cities. In: Office for Official Publications of the European Comunities. Luxembourg, 2000. Disponível em: $<$ http:/ /www.inforegio.cec.eu.int>.

KUMAR, A.K. S. Short term changes in development: tracking inputs, assessing efforts, measuring outcomes. Delhi: Draft for Discussion, 1999.

MARSHALL, T. Cidadania, classe social e status. Rio de Janeiro, Zahar, 1965.

MURRAY, C.J.L.; CHEN, L.C. Understanding Morbidity Change. CHEN, L.C. et al. Health and social change in international perspective. Cambridge: Harvard University Press, 1993. p.87-114.

NICOLAU, J. Sistema eleitoral e reforma politica. Rio de Janeiro: Foglio, 1993.

NUSSBAUM, M.; SEN, A. La calidad de vida (Introdução). México: Fondo de Cultura Económica; The United Nations University, 1998.

PNUD. Relatório do desenvolvimento humano 2000. Lisboa: Trinova, 2000 .

. Relatório do desenvolvimento humano 1999. Lisboa: Trinova, 1999. 
Relatório do desenvolvimento humano no Brasil. 1996. Brasília: 1996.

PNUD et al. Desenvolvimento humano e condições de vida: indicadores brasileiros. Brasília: PNUD, 1998.

PUTNAM, R.D. Comunidade e democracia: a experiência da Itália Moderna. Rio de Janeiro: Fundação Getúlio Vargas, 1996.

SANTOS, W.G. Cidadania e justiça. Rio de Janeiro: Campus, 1979.

TENDLER, J. Good government in the tropics. Baltimore: The John Hopkins University Press, 1997.

TODD, A. Health inequalities in urban areas: guide to the literature. Environment and Urbanization, v.8, n.2, 1996, p.141-152.
TORRES, H.G. Social policies for the urban poor: the role of populations, information systems. Working Papers Series CST/ $L A C$, n.24, Mexico: UNFPA Country Support Team for Latin America \& The Caribbean, jan. 2002.

Haroldo da Gama Torres: Demógrafo, Pesquisador do Cebrap e do Centro de Estudos da Metrópole, Consultor da Fundação Seade.

Maria Paula Ferreira: Estatística, Analista da Fundação Seade, Consultora do Centro de Estudos da Metrópole.

Nádia Pinheiro Dini: Estatística, Gerente de Métodos Quantitativos da Fundação Seade. 